\title{
Synthesis of Conjugated Polymers Possessing Diketopyrrolopyrrole (DPP) Units Bearing Phenyl, Pyridyl, and Thiazolyl Groups by Direct Arylation Polycondensation: Effects of Aromatic Groups in DPP on Physical Properties
}

\author{
Junpei Kuwabara, ${ }^{1}$ Naoto Takase, ${ }^{1}$ Takeshi Yasuda, ${ }^{2}$ Takaki Kanbara ${ }^{1}$ \\ ${ }^{1}$ Tsukuba Research Center for Interdisciplinary Materials Science (TIMS), Graduate School of Pure and \\ Applied Sciences, University of Tsukuba, 1-1-1 Tennodai, Tsukuba, Ibaraki, 305-8573, Japan. \\ 2 Organic Thin-Film Solar Cells Group, Photovoltaic Materials Unit, National Institute for Materials \\ Science (NIMS), 1-2-1 Sengen, Tsukuba, Ibaraki, 305-0047, Japan.
}

Correspondence to: T. Kanbara (E-mail: kanbara@ims.tsukuba.ac.jp)

ABSTRACT: Conjugated polymers containing phenyl-, pyridyl-, and thiazolyl-flanked diketopyrrolopyrrole (DPP) were synthesized by direct arylation polycondensation of 3,4ethylenedioxythiophene (EDOT) derivatives and dibrominated DPP-based monomers, in order to probe the effects of the aromatic groups in the DPP units on the absorption property, energy level, and crystallinity. A polymer possessing thiazolyl-flanked DPP units was found to display longwavelength absorption properties and higher crystallinity than the polymers bearing phenyl- and pyridyl-flanked DPP units. These features of the thiazolyl-based polymer were afforded by its coplanar structure of the main chain. The synthesized polymers showed semiconducting properties in organic field effect transistors (OFETs) and organic photovoltaics (OPVs). Direct arylation polycondensation is an efficient synthetic method that affords a series of DPP-based polymers in a simple fashion and thus helping in a comprehensive understanding on the relationship between the aromatic groups in DPP units and their physical properties.

KEYWORDS: conjugated polymer; polycondensation; structure-property relations; direct arylation; diketopyrrolopyrrole (DPP); organic field effect transistors; organic photovoltaics

\section{INTRODUCTION}

Diketopyrrolopyrroles (DPPs) are considered to be one of the most promising units of conjugated polymer materials that are used in organic field effect transistors (OFETs) and organic photovoltaics (OPVs). ${ }^{1-4}$ The planar and donoracceptor structures inherent to DPPs provide aggregation properties, resulting in high carrier mobility in both devices. A choice of aromatic units in DPPs strongly affects the physical properties of DPP-based conjugated polymers. ${ }^{1-4}$ Initial investigations focused on phenyl-flanked DPPs, ${ }^{5}$ which were derived from a well-known pigment. ${ }^{6-8}$ Subsequent investigations focused on thienyl-flanked DPPs because of their higher degrees of planarity and stronger donoracceptor properties than those of phenyl-flanked DPPs. $^{1-4}$ Along these lines, high-performance conjugated polymers with thieno[3,2b] thiophene-, ${ }^{9,10}$ pyridyl-, ${ }^{11,12}$ and thiazolylflanked DPPs ${ }^{13,14}$ were synthesized and investigated. Among these, the conjugated polymers possessing pyridyl- and thiazolylflanked DPPs displayed n-type semiconducting properties owing to the acceptor properties of the pyridyl and thiazolyl groups. ${ }^{12,14}$ These DPPbased polymers were originally synthesized by polycondensation using cross coupling reactions between organometallic monomers (organoboron or organotin compounds) and dihalogenated monomers. ${ }^{1-4}$ In recent years, 
polycondensation using $\mathrm{C}-\mathrm{H}$ direct arylation has been investigated as an alternative approach, ${ }^{15-29}$ and has been successfully applied in the synthesis of DPP-based conjugated polymers by our group $^{30}$ and several other groups. ${ }^{31-37}$ Because direct arylation polycondensation does not require the preparation of organometallic monomers, a series of conjugated polymers could be synthesized in a simple fashion. ${ }^{15-19}$ Herein, we report the synthesis of conjugated polymers containing phenyl-, pyridyl-, and thiazolyl-flanked DPPs by direct arylation polycondensation. We also discuss the effects of aromatic moieties in the DPP units on the absorption property, energy level, and crystallinity.

\section{EXPERIMENTAL}

\section{Materials}

3,4-Ethylenedioxythiophene (EDOT), palladium acetate $\left(\mathrm{Pd}(\mathrm{OAc})_{2}\right)$, and potassium carbonate $\left(\mathrm{K}_{2} \mathrm{CO}_{3}\right)$ were received from commercial suppliers and used without further purification. Anhydrous dimethylacetamide (DMAc) was purchased from Kanto Chemical and used as a dry solvent. M1, ${ }^{38}$ M2, ${ }^{39} \mathbf{M} 3,{ }^{14}$ and 3-dihexyl-2,3-dihydro-thieno[3, 4- $b$-1,4-dioxin (dihexylEDOT) ${ }^{40}$ were prepared according to the literature methods. Poly(3,4ethylenedioxythiophene)-poly(styrenesulfonate)

(PEDOT:PSS, CLEVIOS P VP Al 4083) was purchased from Heraeus. $\mathrm{PC}_{70} \mathrm{BM}$ (purity $99 \%$ ) was purchased from Solenne. Standard solutions of $\mathrm{Pd}\left(1000 \mathrm{mg} \mathrm{L}^{-1}\right)$ was purchased from Kanto Chemical.

\section{General Measurements and Characterization}

NMR spectra were recorded by AVANCE- 400 and AVANCE-600 NMR spectrometer (Bruker). Gel permeation chromatography (GPC) measurements were carried out using a prominence GPC system (SHIMADZU) equipped with polystyrene gel columns, using $\mathrm{CHCl}_{3}$ as the eluent after calibration with polystyrene standards $\left(40{ }^{\circ} \mathrm{C}\right)$. High-temperature GPC measurements were carried out using a HLC-8321 $\mathrm{GPC} / \mathrm{HT}$ (TOSOH) using o-dichlorobenzene (o$\mathrm{DCB})$ as the eluent after calibration with polystyrene standards $\left(140^{\circ} \mathrm{C}\right)$. MALDI-TOF-MS spectra were recorded on a MALDI TOF/TOF 5800 (AB SCIEX) in a linear mode using trans-2-[3-(4tert-Butylphenyl)-2-methyl-2-

propenylidene]malononitrile (DCTB) as matrix. The HOMO energy levels were estimated by photoelectron yield spectroscopy (PYS) using an AC-3 spectrometer (Riken Keiki). Ultravioletvisible (UV-vis) absorption spectra were recorded using a V-630 spectrometer (JASCO). The amounts of residual $\mathrm{Pd}$ in the polymers were determined by ICP-MS using an ELAN DRC-e ICPMS instrument (Perkin Elmer) after decomposing the weighed samples in analytical grade nitric acid with heating. $X$-ray diffraction patterns were recorded at $298 \mathrm{~K}$ on a Rigaku model MultiFlex Xray diffractometer with a CuKa radiation source. The thermal properties were measured on an EXSTAR TG/DTA6300 instrument. DFT calculations were performed at the B3LYP/631G(d) level with the Gaussian09 Rev. D.01 program. All the manipulations for the reactions were carried out under a nitrogen atmosphere using a glove box or standard Schlenk technique. Microwave reactions were conducted using a CEM Discover and Explorer SP System (CEM). The reaction temperature controls were conducted using Dynamic mode of Synergy Software.

\section{Synthesis of P1}

$\mathrm{Pd}(\mathrm{OAc})_{2}(0.56 \mathrm{mg}, 2.5 \mu \mathrm{mol})$ and $\mathrm{M} 1(224 \mathrm{mg}$, $0.25 \mathrm{mmol}$ ) were weighed in air and placed in a 10-mL microwave vessel with a magnetic stir bar. The vessel was transferred to a glove box under nitrogen atmosphere. To the microwave vessel, potassium pivalate $(87.7 \mathrm{mg}, 0.63 \mathrm{mmol})$, dihexyIEDOT (78.8 $\mu \mathrm{L}, 0.25 \mathrm{mmol})$, and degassed DMAc $(2.5 \mathrm{~mL})$ were added. The vessel was sealed with a septum and taken out from the glove box. The sealed vessel was placed in the microwave reactor and heated at $100{ }^{\circ} \mathrm{C}$ for $1 \mathrm{~h}$. After cooling to room temperature, EDOT (13.3 $\mu \mathrm{L}, 0.13 \mathrm{mmol}), \mathrm{Pd}(\mathrm{OAc})_{2}(0.56 \mathrm{mg}, 2.5 \mu \mathrm{mol})$, and DMAc $(0.63 \mathrm{~mL})$ were added to the reaction mixture in the glove box. The mixture was heated at $100{ }^{\circ} \mathrm{C}$ for $30 \mathrm{~min}$. After the reaction, an aqueous solution of ethylenediaminetetraacetic acid disodium salt $(\mathrm{pH}=8)$ was added. The suspension was stirred for $2 \mathrm{~h}$ at room 
temperature. The precipitate was collected by filtration and washed with $0.1 \mathrm{M} \mathrm{HCl}$ solution, distilled water, methanol, and hexane. The precipitate was dissolved in $\mathrm{CHCl}_{3}$, and the solution was filtered through Celite to remove insoluble materials. Reprecipitation from chloroform/methanol afforded the polymer as a purple solid. The solid was dispersed in hexane (30 $\mathrm{mL})$ and the suspension was stirred for overnight to remove a low-molecular-weight fraction which was soluble in hexane. The hexane-insoluble fraction was collected by filtration. The solid was dissolved with chloroform and reprecipitation from chloroform/methanol afforded P1 with a molecular weight of $47300\left(M_{\mathrm{w}} / M_{\mathrm{n}}=4.22\right)$ in $37 \%$ yield. ${ }^{1} \mathrm{H}$ NMR (600 MHz, $\left.\mathrm{C}_{2} \mathrm{D}_{2} \mathrm{Cl}_{4}, 120{ }^{\circ} \mathrm{C}\right): \delta 7.94$ (br, 4H), $7.84(\mathrm{br}, 4 \mathrm{H}), 4.34(\mathrm{~d}, J=7.8 \mathrm{~Hz}, 2 \mathrm{H})$, $3.80(\mathrm{br}, 4 \mathrm{H}), 1.89-1.78(\mathrm{~m}, 2 \mathrm{H}), 1.72-1.11(\mathrm{~m}$, $68 \mathrm{H}), 0.94-0.81(\mathrm{~m}, 18 \mathrm{H}) .{ }^{13} \mathrm{C}\left\{{ }^{1} \mathrm{H}\right\} \mathrm{NMR}(150 \mathrm{MHz}$, $\left.\mathrm{C}_{2} \mathrm{D}_{2} \mathrm{Cl}_{4}, 100{ }^{\circ} \mathrm{C}\right): \delta 162.66,147.69,139.97,135.52$, $128.96,126.56,125.68,115.62,110.18,76.92$, $45.91,37.31,31.47,31.39,29.69,29.29,29.20$, 28.98, 28.76, 28.45, 26.14, 25.53, 22.34, 22.30, 13.69 (6 signals of the alkyl groups were overlapped).

\section{Synthesis of $\mathbf{P 2}$}

P2 was prepared according to the procedure for P1 using M2 (224 mg, $0.25 \mathrm{mmol}$ ) instead of M1. $M_{\mathrm{n}}=93700\left(M_{\mathrm{w}} / M_{\mathrm{n}}=3.45\right), 91 \%$ yield. ${ }^{1} \mathrm{H}$ NMR $\left(600 \mathrm{MHz}, \mathrm{C}_{2} \mathrm{D}_{2} \mathrm{Cl}_{4}, 100{ }^{\circ} \mathrm{C}\right): \delta 9.10(\mathrm{~s}, 2 \mathrm{H}), 9.03(\mathrm{~d}$, $J=7.8 \mathrm{~Hz}, 2 \mathrm{H}), 8.26(\mathrm{~d}, J=7.8 \mathrm{~Hz}, 2 \mathrm{H}), 4.37(\mathrm{br}$, $6 \mathrm{H}), 1.87-1.13(\mathrm{~m}, 70 \mathrm{H}), 0.88(\mathrm{t}, J=6.6 \mathrm{~Hz}, 6 \mathrm{H})$, $0.83(\mathrm{t}, J=6.6 \mathrm{~Hz}, 12 \mathrm{H}) \cdot{ }^{13} \mathrm{C}\left\{{ }^{1} \mathrm{H}\right\} \operatorname{NMR}(150 \mathrm{MHz}$, $\left.\mathrm{C}_{2} \mathrm{D}_{2} \mathrm{Cl}_{4}, 100^{\circ} \mathrm{C}\right): \delta 162.58,145.68,145.35,144.95$, $140.93,132.62,129.81,129.82,127.06,113.80$, $111.52,77.26,46.66,38.26,31.79,31.65,31.56$, $31.33,29.84,29.45,29.29,29.02,28.75,28.41$, 26.44, 26.40, 25.49, 22.34, 22.25, 13.71, 13.62 (3 signals of the alkyl group were overlapped).

\section{Synthesis of $\mathbf{P 3}$}

P3 was prepared in $0.20 \mathrm{mmol}$ scale according to the procedure for P1 using M3 (182 mg, 0.20 $\mathrm{mmol}$ ) instead of $\mathbf{M} 1$. DihexylEDOT $(31.5 \mu \mathrm{L})$ was used as an end-capping reagent instead of EDOT. The low-molecular-weight fraction was removed by washing with hexamethyldisiloxane instead of hexane $(30 \mathrm{~mL}) \cdot M_{\mathrm{n}}=23300\left(M_{\mathrm{w}} / M_{\mathrm{n}}=1.74\right), 63 \%$ yield. ${ }^{1} \mathrm{H}$ NMR (600 MHz, $\left.\mathrm{C}_{2} \mathrm{D}_{2} \mathrm{Cl}_{4}, 100{ }^{\circ} \mathrm{C}\right): \delta 8.19$ $(\mathrm{s}, 2 \mathrm{H}), 4.43(\mathrm{br}, 2 \mathrm{H}), 4.31$ (br, $4 \mathrm{H}), 2.00-1.87(\mathrm{br}$, $2 \mathrm{H}), 1.86-1.06(\mathrm{~m}, 68 \mathrm{H}), 0.96-0.70(\mathrm{~m}, 18 \mathrm{H})$. ${ }^{13} \mathrm{C}\left\{{ }^{1} \mathrm{H}\right\}$ NMR $\left(150 \mathrm{MHz}, \mathrm{C}_{2} \mathrm{D}_{2} \mathrm{Cl}_{4}, 100{ }^{\circ} \mathrm{C}\right): \delta 160.90$, $152.82,140.19,139.91,136.95,134.34,110.99$, $108.62,77.98,46.98,37.96,31.79,31.66,31.56$, $31.39,31.30,29.86,29.46,29.29,29.04,28.72$, $28.40,26.46,26.39,25.30,22.36,22.30,22.25$, $13.70,13.67$ (1 signal of the alkyl group was overlapped).

\section{Pd removal procedure}

To a solution of $\mathbf{P 1}(84.2 \mathrm{mg})$ in $\mathrm{CHCl}_{3}(100 \mathrm{~mL})$, a solution of $\mathrm{NaS}_{2} \mathrm{CN}\left(\mathrm{C}_{2} \mathrm{H}_{5}\right)_{2}(20 \mathrm{mg})$ in water (100 $\mathrm{mL}$ ) was added. The two-phase mixture was vigorously stirred for $24 \mathrm{~h}$ and the organic phase was separated from the aqueous phase and black precipitate composed of $\mathrm{Pd}$. This procedure was repeated again. The organic phase was filtered through Celite and reprecipitation from a chloroform/methanol mixture afforded P1 (72.8 $\mathrm{mg}, 86 \%$ recovery).

\section{Fabrication and characterization of OFETs}

To estimate the hole mobilities of the polymers, OFETs with a top-contact geometry were fabricated and characterized as follows. A glass/Au gate electrode/Parylene-C insulator substrate was prepared according to the previously reported methods. ${ }^{41}$ The P1-P3 were spin-coated from $O-D C B$ solution onto the Parylene- $C$ layer. The coated substrate was then transferred to a $\mathrm{N}_{2}$-filled glove box where it was dried for $10 \mathrm{~min}$ at $110^{\circ} \mathrm{C}$. Au $(40 \mathrm{~nm})$ sourcedrain electrodes were thermally evaporated onto the substrates through shadow masks. The channel length and width were fixed at $75 \mu \mathrm{m}$ and $5 \mathrm{~mm}$, respectively. The OFET measurements were conducted using a Keithley 2636A System Source Meter.

\section{Fabrication and characterization of OPV cells} The OPV cells were fabricated in the following configuration: ITO/PEDOT:PSS/BHJ layer/LiF/Al. The patterned ITO (conductivity: $10 \Omega /$ square) glass was precleaned in an ultrasonic bath of

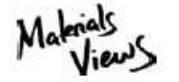

WWW.MATERIALSVIEWS.COM 
acetone and ethanol, and then treated in an ultraviolet-ozone chamber. A thin layer $(40 \mathrm{~nm})$ of PEDOT:PSS was spin-coated onto the ITO at $3,000 \mathrm{rpm}$ and air-dried at $110^{\circ} \mathrm{C}$ for $10 \mathrm{~min}$ on a hot plate. The substrate was then transferred to a $\mathrm{N}_{2}$-filled glove box where it was re-dried at $110{ }^{\circ} \mathrm{C}$ for $10 \mathrm{~min}$ on a hot plate. An o-DCB solution of the $\mathbf{P 1}$ and $\mathrm{PC}_{70} \mathrm{BM}$ blended in a 1:3 ratio was subsequently spin-coated onto the PEDOT:PSS surface to form the $\mathrm{BHJ}$ layer. The substrates with the $\mathrm{BHJ}$ layers were dried for $10 \mathrm{~min}$ at $110{ }^{\circ} \mathrm{C}$ for the film spin-cast using the $o-D C B$ solution. LiF ( 1 $\mathrm{nm})$ and $\mathrm{Al}(80 \mathrm{~nm})$ were then deposited onto the active layer by conventional thermal evaporation at a chamber pressure lower than $5 \times 10^{-4} \mathrm{~Pa}$, which provided the devices with an active area of $5 \times 2 \mathrm{~mm}^{2}$. The thicknesses of BHJ and PEDOT:PSS layers were measured using an automatic microfigure measuring instrument (SURFCORDER ET200, Kosaka Laboratory, Ltd.). The current density-voltage $(\mathrm{J}-\mathrm{V})$ curves were measured using an ADCMT 6244 DC voltage current source/monitor under AM 1.5 solar-simulated light irradiation of $100 \mathrm{~mW} \mathrm{~cm}^{-2}$ (OTENTO-SUN III, Bunkoh-Keiki Co.). The external quantum efficiency (EQE) and the internal quantum efficiency (IQE) were measured using an SM-250 system (Bunkoh-Keiki Co., Ltd.) with an integrating sphere to determine the reflectance $(R)$ of the $\mathrm{BHJ}$ OPVs for estimating IQE=EQE/(1-R). As a part of the structural characterizations, the surface morphologies were studied using atomic force microscopy (AFM, Nanocute, SII Nano Technology, Inc.).

\section{RESULTS AND DISCUSSION}

\section{Synthesis of Polymers}

Direct arylation polycondensation between dibrominated DPP monomers and EDOT was investigated because the high reactivity of its $\mathrm{C}-\mathrm{H}$ bond makes it an ideal candidate for direct arylation reactions. ${ }^{42-47}$ In addition, EDOT is expected to serve as a strong electron-donor unit in the polymers. Because a combination of direct arylation polycondensation and microwave heating has been reported to afford highmolecular-weight polymers, ${ }^{45}$ reaction conditions under microwave heating and the substrate effect of alkyl chains on DPP were investigated in the reaction of EDOT with a dibrominated phenyl-flanked DPP (Table 1). ${ }^{45}$

TABLE 1 Optimization of reaction conditions and alkyl chains on direct arylation polycondensation of EDOT with dibrominated phenyl-flanked DPPs

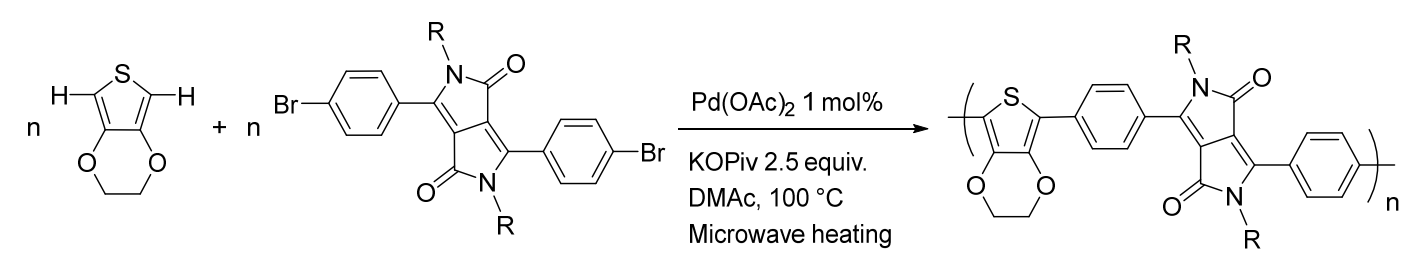

\begin{tabular}{ccccccc}
\hline Entry & $\mathrm{R}^{\mathrm{a}}$ & Time $/ \mathrm{h}$ & Concentration / M & Yield / \% & $M_{\mathrm{n}}$ & $M_{\mathrm{n}} / M_{\mathrm{n}}$ \\
\hline 1 & OD & $0.5 \mathrm{~h}$ & 0.2 & 22 & 4600 & 1.96 \\
\hline $2^{2}$ & OD & $1 \mathrm{~h}$ & 0.2 & 20 & 6200 & 1.78 \\
\hline $3^{\mathrm{b}}$ & OD & $1 \mathrm{~h}$ & 0.1 & 65 & 15600 & 2.43 \\
$4^{\mathrm{b}}$ & $\mathrm{HD}$ & $1 \mathrm{~h}$ & 0.1 & 87 & 20400 & 3.89 \\
$5^{\mathrm{b}}$ & EH & $1 \mathrm{~h}$ & 0.1 & 80 & 20900 & 2.82
\end{tabular}

${ }^{a}$ OD: 2-octyldodecyl, HD: 2-hexyldecyl, EH: 2-ethylhexyl. ${ }^{b}$ Average of two or more runs. 
The reaction of the 2-octyldodecyl-substituted DPP monomer with EDOT afforded an oligomeric product in low yields (Table 1, Entry 1). A longer reaction time did not increase the yield or the molecular weight of the product (Entry 2). However, when the reaction was carried out under a lower concentration of the monomers, both the yield and molecular weight improved (Entry 3). This concentration effect might be explained by the low solubility of the DPP monomer with a long alkyl chain in a polar solvent, $\mathrm{N}, \mathrm{N}$-dimethylacetamide (DMAc) because the 2-octyldodecyl-substituted DPP monomer was separated from the reaction media as oil droplet before heating. In terms of the alkyl chains, the 2-hexyldodecyl group appeared to be the optimal chain length among the three (i.e., 2octyldodecyl, 2-hexyldecyl, and 2-ethylhexyl) in both yield and molecular weight (Entries 3-5). The molecular weight of 20400 is also comparable to that of the same polymer recently synthesized by polycondensation using the Migita-Kosugi-Stille coupling reaction $\left(M_{\mathrm{n}}=\right.$ 16700). ${ }^{48}$ It should be noted that only $1 \mathrm{~mol} \%$ of the Pd catalyst is needed and the polymer is obtained within $1 \mathrm{~h}$, presumably owing to uniform and rapid microwave heating. ${ }^{45,49}$

TABLE 2 Results of Polycondensation

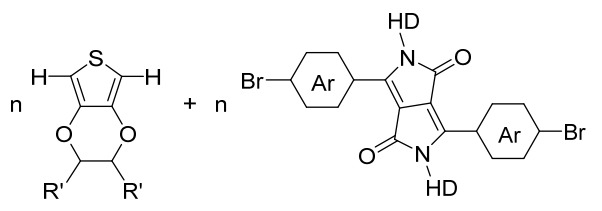<smiles>COCCOCC(=O)OC</smiles>

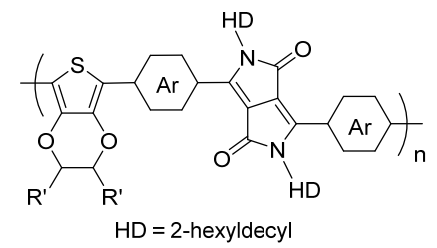<smiles>[2H]N1C(=O)C2C(C(=O)C(=O)C3C(C(=O)N([2H])C3c3ccc(Br)cc3)C2c2ccc(Br)cc2)C1c1ccc(Br)cc1</smiles>

M1<smiles>[2H]N1C(=O)C2C(c3ccc(Br)cn3)C(=O)N([2H])C(c3ccc(Br)cn3)C2C1=O</smiles>

M2

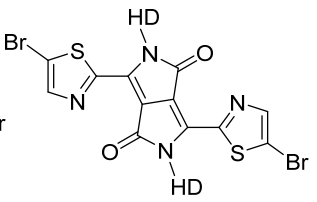

M3

\begin{tabular}{|c|c|c|c|c|c|c|c|}
\hline Entry & $\mathrm{R}^{\prime}$ & Monomer & Polymer & Yield / \% & $M_{\mathrm{n}}$ & $M_{\mathrm{w}} / M_{\mathrm{n}}$ & Pd residue ${ }^{a} / \mathrm{ppm}$ \\
\hline $1^{b}$ & $\mathrm{H}$ & M1 & & 94 & 20400 & 3.89 & $-c$ \\
\hline 2 & $\mathrm{H}$ & M2 & & 94 & 22300 & 6.90 & $-c$ \\
\hline 3 & $\mathrm{H}$ & M3 & & 71 & 1200 & 9.51 & $-c$ \\
\hline 4 & $\mathrm{C}_{6} \mathrm{H}_{13}$ & M1 & P1 & $37^{d}$ & $\begin{array}{c}47300 \\
(7800)^{f}\end{array}$ & $\begin{array}{c}4.22 \\
(4.58)^{f}\end{array}$ & 41 \\
\hline 5 & $\mathrm{C}_{6} \mathrm{H}_{13}$ & M2 & P2 & $91^{d}$ & $\begin{array}{c}93700 \\
(60100)^{f}\end{array}$ & $\begin{array}{c}3.45 \\
(2.75)^{f}\end{array}$ & 372 \\
\hline 6 & $\mathrm{C}_{6} \mathrm{H}_{13}$ & M3 & P3 & $63^{e}$ & $\begin{array}{c}23300 \\
(17500)^{f}\end{array}$ & $\begin{array}{c}1.74 \\
(1.68)^{f}\end{array}$ & 304 \\
\hline
\end{tabular}

${ }^{a}$ Measured by ICP-MS after washing with aqueous solution of $\mathrm{NaS}_{2} \mathrm{CN}\left(\mathrm{C}_{2} \mathrm{H}_{5}\right)_{2},{ }^{b}$ Table 1 , Entry 4, ${ }^{\mathrm{c}}$ Not determined, ${ }^{d}$ Yield after washing with hexane, ${ }^{e}$ Result after washing with hexamethyldisiloxane. ${ }^{f}$ Results in parentheses were obtained from high-temperature GPC (o-dichlorobenzene, $140^{\circ} \mathrm{C}$ ). 


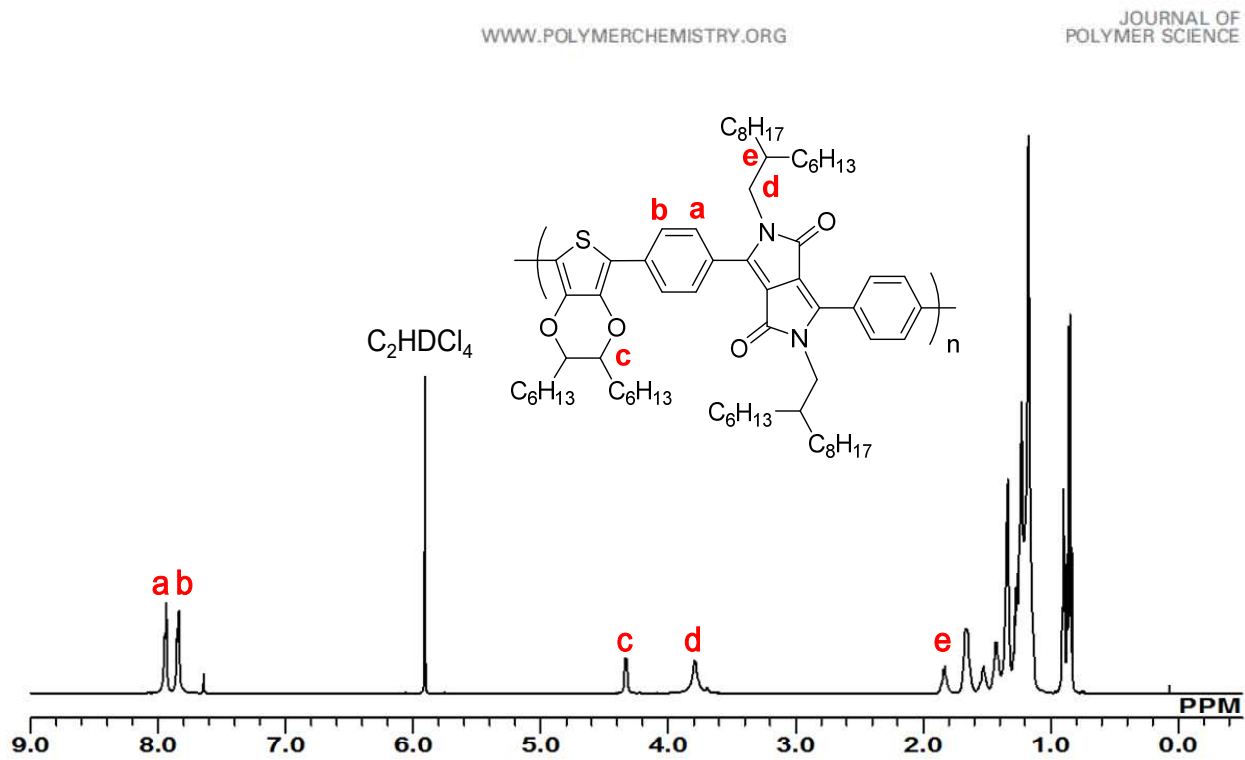

FIGURE $1^{1} \mathrm{H}$ NMR spectrum of $\mathbf{P 1}$ (600 MHz in $\mathrm{C}_{2} \mathrm{D}_{2} \mathrm{Cl}_{4}$ at $393 \mathrm{~K}$ ).

The reactions of pyridyl- and thiazolyl-flanked DPPs with EDOT were conducted under the optimized reaction conditions for the phenylflanked DPP monomer (Table 2, Entries 1-3). The polycondensation reaction of the pyridylflanked DPP monomer (M2) afforded the corresponding polymer in a good yield (Entry 2). However, the reaction of the thiazolyl-flanked DPP monomer (M3) afforded only oligomeric products (Entry 3 ). Because the low solubility of the formed polymer was considered to prohibit the propagation reaction, an alkylated EDOT ( $\mathrm{R}^{\prime}$ $=\mathrm{C}_{6} \mathrm{H}_{13}$, dihexylEDOT) was used in the reaction with M1-M3 under the same reaction conditions (Entries 4-6) in order to obtain a higher-molecular-weight product. ${ }^{39,50}$ The introduction of the hexyl groups dramatically increased the solubility of polymers in organic solvents; most of the polymer (P1) produced from dihexyIEDOT and $\mathbf{M} 1$ was hexane soluble. Therefore, the yield of $\mathbf{P 1}$ after washing with hexane was 37\% (Entry 4). The reactions of $\mathbf{M} 2$ or M3 with dihexylEDOT afforded highermolecular-weight polymers than their corresponding EDOT-based polymers (Entries 5 and 6). In contrast to successful polymerization of $\mathbf{M} 2$ and $\mathbf{M} 3$, the reaction with a thienylflanked DPP afforded insoluble products presumably due to a cross-linking side reaction at the undesired $\mathrm{C}-\mathrm{H}$ moiety in the thienyl group. ${ }^{22}$ The ${ }^{1} \mathrm{H}$ NMR spectrum of $\mathbf{P} 1$ shows sharp signals corresponding to the repeating units at $120{ }^{\circ} \mathrm{C}$ (Fig. 1), while broad signals are predominant at room temperature owing to aggregation (Fig. S-4). The signals at $7.64 \mathrm{ppm}$ can be assigned to the protons of the brominated phenyl group in the terminal DPP unit (Fig. S-4). This observation is further supported by the MALDI-TOF-MS results of $\mathbf{P} \mathbf{1}$ (Fig. S-6). The MS spectrum also indicates the presence of a small amount of defects caused by a homo coupling reaction of dihexyIEDOT. ${ }^{51-}$ ${ }^{53}$ To evaluate the aggregation effect on the GPC measurements, high-temperature GPC measurements $\left(140{ }^{\circ} \mathrm{C}\right)$ were conducted in addition to the normal GPC measurements $\left(40^{\circ} \mathrm{C}\right.$ ) (Table 2). Because the high-temperature GPC shows smaller molecular weight than those from the normal GPC, the aggregation effects are considered to induce overestimation of the molecular weight of the polymers. The structures of $\mathbf{P 2}$ and $\mathbf{P} \mathbf{3}$ were also characterized by ${ }^{1} \mathrm{H}$ NMR, ${ }^{13} \mathrm{C}\left\{{ }^{1} \mathrm{H}\right\}$ NMR, and MALDI-TOF-MS (Fig. S-7-S1-2). The Pd catalyst residue was removed from $\mathbf{P 1 - P 3}$ by washing with an aqueous solution of sodium $\mathrm{N}, \mathrm{N}$ diethyldithiocarbamate $\left(\mathrm{NaS}_{2} \mathrm{CN}\left(\mathrm{C}_{2} \mathrm{H}_{5}\right)_{2}\right)$ at room temperature. ${ }^{54,55}$ Residual amounts of $\mathrm{Pd}$ were measured by ICP-MS. After purification, the residual amount of Pd in $\mathbf{P 1}$ was $41 \mathrm{ppm}$, which was significantly higher than that of the EDOT-fluorene polymer (PO, 2.4 ppm, Fig. 2), 
which was purified by the same method. ${ }^{55}$ Moreover, P2 and P3 contained even more Pd residue (372 and $304 \mathrm{ppm}$ ) after purification. The difficulties in removing the $\mathrm{Pd}$ catalyst residue from these polymers (P1, P2, and P3) could be explained by the presence of several coordination sites such as the carbonyl group and imine nitrogen.

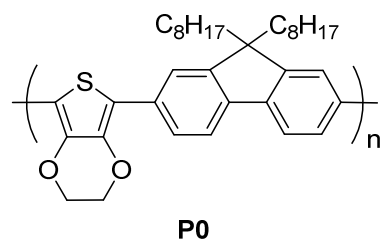

FIGURE 2 The chemical structure of the reference polymer.

\section{Physical Properties}

The UV-vis absorption spectra of P1-P3 and the reference polymer $(\mathbf{P O})^{46}$ are shown in Fig. 3. For all the four polymers, the solution phase and film state absorption spectra were similar to each other. Owing to the presence of DPP units, P1-P3 show long-wavelength absorption compared to P0: the absorption coefficients of P0-P3 are in the same range (Table S-1). Absorption region clearly depends on the aromatic groups of the DPP units. The order of maximum absorption wavelength $\left(\lambda_{\max }\right)$ is $\mathbf{P} \mathbf{1}<$ $\mathbf{P 2}<\mathbf{P 3}$. The comparison of the physical properties of a pyridyl-containing DPP polymer and that of a thiazolyl-containing DPP polymer have not yet been reported. Therefore, we further investigated the difference in the absorption properties by using the results of density-functional theory (DFT) calculations. Energy-minimized structures of the modeling compounds for P1-P3 are shown in Fig. 4. The result shows that $\mathbf{P 1}$ has large dihedral angles around the phenyl moiety $\left(23.82^{\circ}\right.$ and $\left.14.32^{\circ}\right){ }^{2}$
In the case of $\mathbf{P 2}$, the dihedral angle between the pyridyl moiety and the DPP core decreases to $0.17^{\circ}$ owing to less steric hindrance caused by the $\mathrm{N}$ moiety in the pyridyl unit versus the $\mathrm{C}$ $\mathrm{H}$ group in the phenyl unit. ${ }^{12}$ Moreover, $\mathbf{P 3}$ also has a small dihedral angle between the thiazolyl and EDOT units $\left(0.23^{\circ}\right)$, presumably due to the low steric hindrance of a five-membered thiazolyl ring. In addition, an intramolecular S...O interaction may also contribute to the planner structure of P3. ${ }^{56}$ Coplanarity of the main chain structures is likely to affect the absorption properties.
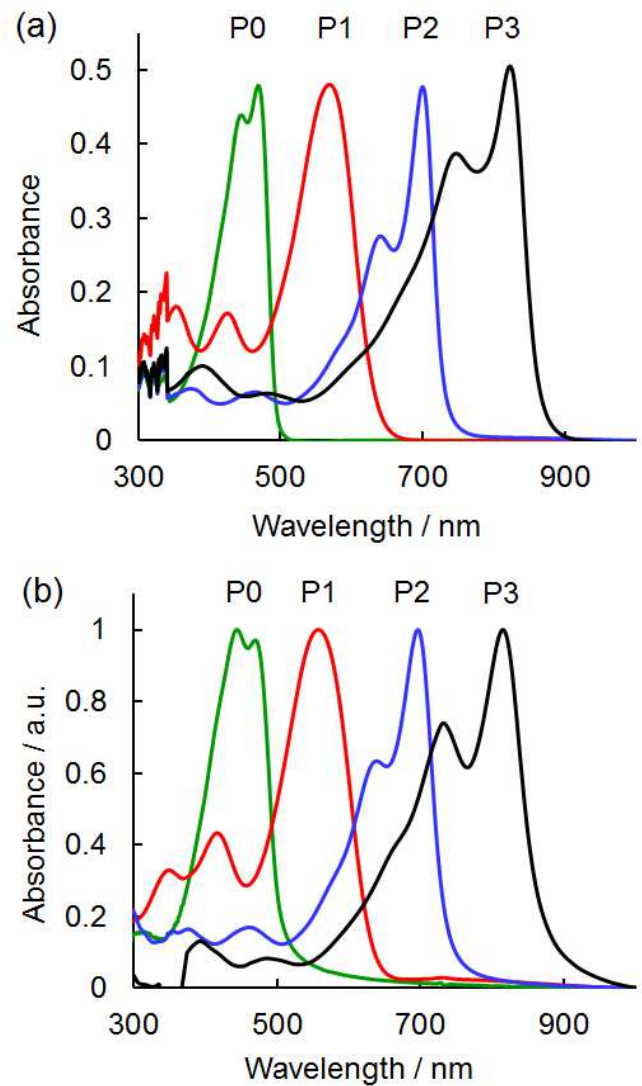

FIGURE 3 UV-vis absorption spectra of P0-P3 (a) in $\mathrm{CHCl}_{3}\left(1.0 \times 10^{-5} \mathrm{M}\right)$ and $(\mathrm{b})$ in the film state. 

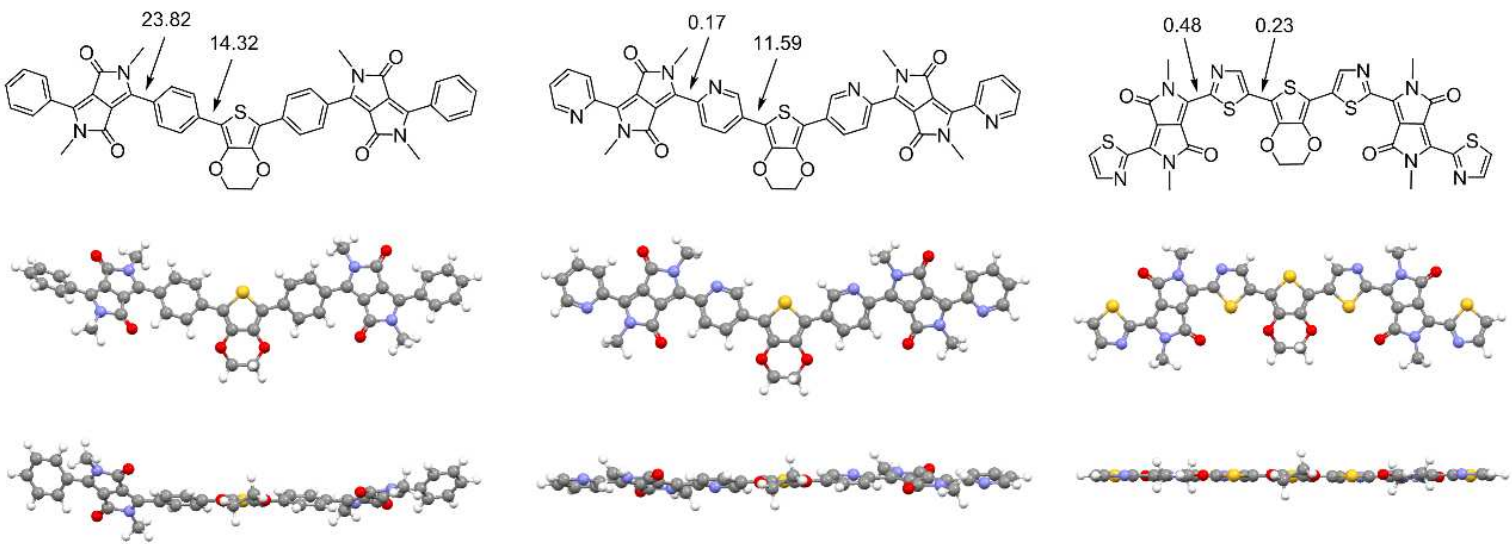

FIGURE 4 Energy-minimized structures of the model compounds for P1, P2, and P3 obtained by DFT calculations at a B3LYP 6-31G(d) level.

TABLE 3 Physical properties and energy levels of polymers

\begin{tabular}{|c|c|c|c|c|c|c|}
\hline Polymer & $\lambda_{\max }{ }^{a} / \mathrm{nm}$ & $\lambda_{\max }{ }^{b} / \mathrm{nm}$ & $E_{g}{ }^{\text {opt c }} / \mathrm{eV}$ & HOMO $^{d} / \mathrm{eV}$ & LUMO $^{\text {e }} / \mathrm{eV}$ & $T_{\mathrm{d}}^{\mathrm{f}} / \mathrm{oC}$ \\
\hline P1 & 568 & 558 & 1.98 & -5.34 & -3.36 & 343 \\
\hline P2 & 700 & 696 & 1.70 & -5.46 & -3.76 & 334 \\
\hline P3 & 822 & 814 & 1.44 & -5.23 & -3.79 & 347 \\
\hline
\end{tabular}

${ }^{a}$ In $\mathrm{CHCl}_{3}\left(1.0 \times 10^{-5} \mathrm{M}\right) .{ }^{\mathrm{b}}$ In the film state. ${ }^{\mathrm{c}}$ Estimated from the absorption onset in the film state. ${ }^{\mathrm{d}}$ Estimated from PYS. ${ }^{\text {e }} \mathrm{E}_{\mathrm{LUMO}}=\mathrm{E}_{\mathrm{g}}{ }^{\mathrm{opt}}+\mathrm{E}_{\text {HOMO }}{ }^{\mathrm{f}}$ The $5 \%$ weight-loss temperature under inert atmosphere.

To investigate the electronic effects of the aromatic group, HOMO and LUMO energy levels were determined by the results of PYS and optical bandgaps (Table 3). The deep HOMO level of P2 is due to the strong acceptor property of the pyridyl group. ${ }^{12}$ Although the thiazolyl group is also known to act as an acceptor unit, ${ }^{14}$ the HOMO level of P3 is the highest among the three polymers. DFT calculations suggest that the HOMO of P3 is delocalized over all units, while the HOMO of $\mathbf{P 2}$ is localized on the EDOT and DPP cores (Fig. S-13). Therefore, the efficient conjugation on the main chain in P3 is responsible for the lower band gap and the higher HOMO level than P2.

\section{X-Ray Diffraction (XRD) Analysis}

The crystallinity of P1-P3 was evaluated by XRD analysis before and after thermal annealing at $200{ }^{\circ} \mathrm{C}$ (Fig. 5 and Table 4). The XRD patterns of P1-P3 exhibited diffraction peaks with a scattering angle $(2 \theta)$ of around $6^{\circ}$, which could be assigned to diffractions arising from lamellar structures. In addition, relatively weak diffractions were observed around $21^{\circ}-23^{\circ}$, corresponding to a $\pi-\pi$ stacking distance. The thermal annealing treatments expanded the lamellar distances and shortened the $\pi-\pi$ stacking distances. The lamellar peak in P3 was significantly sharpened by thermal annealing in comparison to $\mathbf{P} \mathbf{1}$ and $\mathbf{P 2}$, presumably owing to the coplanar structure of the main chain in P3. The crystalline nature of P1-P3 is in sharp contrast to the amorphous nature of P0. ${ }^{46}$ 

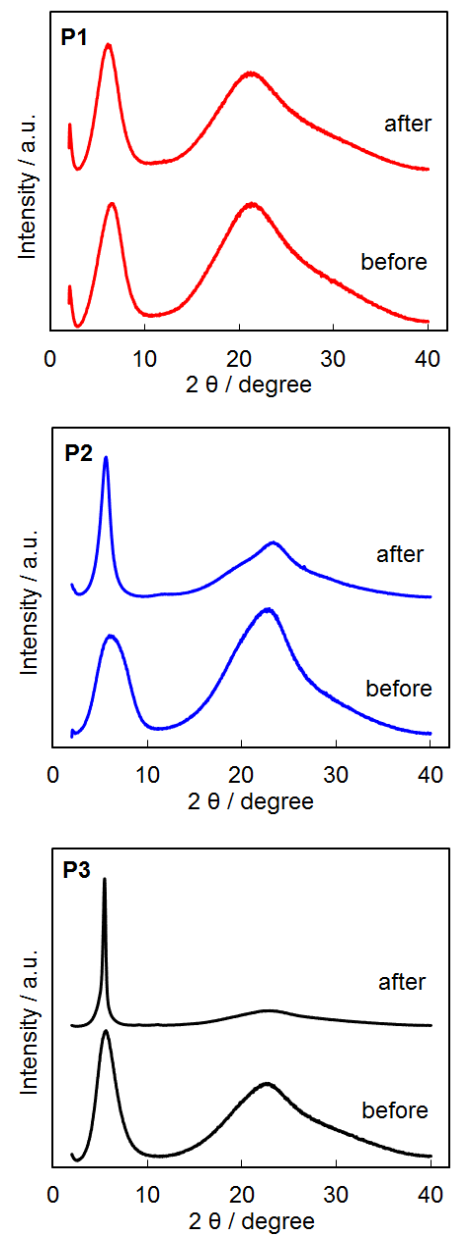

\section{OFETs and OPV Properties}

P1-P3 were evaluated for their semiconducting properties in OFETs and OPVs. The details of the OFET and OPV fabrication are described in the experimental section. The OFETs showed moderate field-effect hole motilities $\left(\mu_{\mathrm{h}}\right)$ in P1-P3 (Table 5). Bulk heterojunction (BHJ) OPVs were fabricated with $\mathbf{P 1}$ and $\mathrm{PC}_{70} \mathrm{BM}$ on several blend ratios with various thicknesses (Table 6 and S-2). The OPV fabricated using $\mathbf{P 1}: \mathrm{PC}_{70} \mathrm{BM}$ at a $1: 3$ mixing ratio with thickness $110 \mathrm{~nm}$ yielded the PCE of $0.96 \%$ (Table 6, Entry 1). The PCEs increased as the thickness decreased (Entries 2 and 3 ). The surface morphology of the active layers was evaluated by AFM (Fig. 6). In comparison with a smooth surface of $\mathbf{P 1}$ (Fig. 6a), a $\mathrm{BHJ}$ film with $\mathbf{P 1}$ and $\mathrm{PC}_{70} \mathrm{BM}$ was found to be more rough, indicating a substantial phase separation (Fig. 6b). The addition of 3\% 1,8diodooctane (DIO) in $o$-DCB decreased the domain size (Fig. 6c). On decreasing the domain size by adding DIO, the PCE slightly increased to 2.20\% (Table 6, Entry 4). Both P2 and P3 show strong aggregation behavior, and hence, they are unsuitable for obtaining appropriate phase separation (Fig. S-18).

FIGURE 5 X-ray diffraction patterns of P1-P3 before and after annealing at $200^{\circ} \mathrm{C}$.

TABLE 4 Results of XRD measurements

\begin{tabular}{|c|c|c|c|}
\hline Polymer & $2 \theta / \mathrm{rad}$ & $d$-spacing / $\AA$ & Harf-value width ${ }^{a} /$ rad. \\
\hline P1 & $6.49,21.31$ & $13.60,4.16$ & 3.66 \\
\hline P1-annealed ${ }^{b}$ & $6.11,21.42$ & $14.46,4.15$ & 3.22 \\
\hline $\mathrm{P} 2$ & $6.18,21.31$ & $14.32,3.96$ & 3.78 \\
\hline P2-annealed ${ }^{\mathrm{b}}$ & $5.66,23.61$ & $15.62,3.77$ & 1.30 \\
\hline P3 & $5.62,22,54$ & $15.73,3.94$ & 2.64 \\
\hline P3-annealed ${ }^{\mathrm{b}}$ & $5.47,22.74$ & $16.14,3.91$ & 0.37 \\
\hline
\end{tabular}

${ }^{a}$ Harf-value width of the first diffraction peak. ${ }^{b}$ Annealed at $200{ }^{\circ} \mathrm{C}$ for 30 min under $\mathrm{N}_{2}$. 
TABLE 5 OFET characteristics ${ }^{\text {a }}$

\begin{tabular}{cccc}
\hline Polymer & $\mu_{\mathrm{h}}{ }^{\mathrm{b}} / \mathrm{cm}^{2} \mathrm{~V}^{-1} \mathrm{~s}^{-1}$ & on/off ratio & $V_{\text {th }}{ }^{\mathrm{c}} / \mathrm{V}$ \\
P1 & $5.6 \pm 0.8 \times 10^{-5}$ & $1.3 \pm 0.2 \times 10^{3}$ & $-33 \pm 4$ \\
P2 & $2.2 \pm 0.9 \times 10^{-4}$ & $2 \pm 1 \times 10^{3}$ & $-52 \pm 2$ \\
P3 & $7.3 \pm 0.3 \times 10^{-5}$ & $1.1 \pm 0.3 \times 10^{3}$ & $-36 \pm 3$
\end{tabular}

a The average values with standard deviations were calculated from the results of three or more OFET samples. OFET configuration; Glass/Au gate electrode/Parylene-C insulator/Polymer/Au source-drain electrodes. ${ }^{\mathrm{b}}$ Field-effect hole mobility. ${ }^{\mathrm{c}}$ Threshold voltage.

TABLE 6 OPV characteristics of P1 ${ }^{\text {a }}$

\begin{tabular}{ccccccc}
\hline Entry & Thickness & Additive & $J_{\mathrm{sc}}{ }^{\mathrm{b}} / \mathrm{mAcm}^{-2}$ & $V_{\mathrm{oc}}{ }^{\mathrm{b}} / \mathrm{V}$ & $F F^{\mathrm{b}}$ & $\mathrm{PCE}^{\mathrm{b}} / \%$ \\
\hline 1 & 111 & & 2.33 & 0.90 & 0.46 & $0.96 \pm 0.04$ \\
\hline 2 & 82 & & 3.43 & 0.90 & 0.50 & $1.55 \pm 0.06$ \\
\hline 3 & 55 & & 4.16 & 0.86 & 0.56 & $2.01 \pm 0.17$ \\
4 & 57 & $\mathrm{DIO}^{\mathrm{c}}$ & 4.63 & 0.88 & 0.54 & $2.20 \pm 0.07$ \\
\hline
\end{tabular}

a OPV configuration; ITO/PEDOT:PSS (40 nm)/P1:PC 70 BM(1:3)/LiF(1 nm)/Al(80 nm). Illuminated at 100 $\mathrm{mWcm}{ }^{-2}$ of AM 1.5; ${ }^{\mathrm{b}}$ Average values at least 3 runs; ${ }^{\mathrm{c}} 3$ vol\% 1,8-diiodooctane (DIO).

(a)

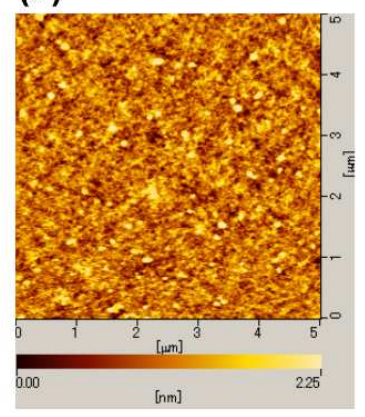

(b)

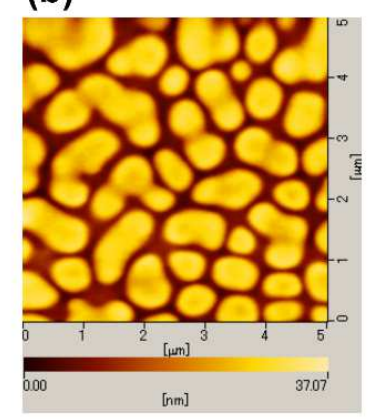

(c)

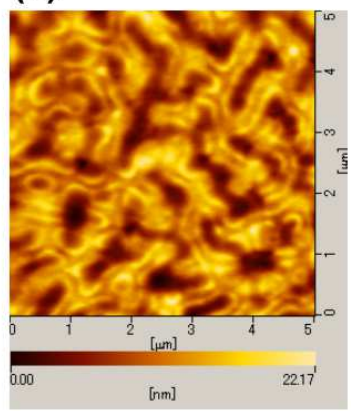

FIGURE 6 AFM images $\left(5 \times 5 \mu \mathrm{m}^{2}\right)$ of thin films of (a) P1 (RMS: $0.3585 \mathrm{~nm}$ ), (b) P1:PC 70 BM (1:3) (RMS: $8.745 \mathrm{~nm}$ ) fabricated by spin coating from o-DCB solution, and (c) P1:PC 70 $_{0} B M$ (1:3) (RMS: $3.652 \mathrm{~nm}$ ) fabricated by spin coating from $o-D C B$ solution containing $3 \%$ DIO. 


\section{CONCLUSION}

Three kinds of DPP-based conjugated polymers were synthesized by direct arylation polycondensation under microwave heating. The high reactivity of the $\mathrm{C}-\mathrm{H}$ bond in the EDOT derivative enabled smooth direct arylation polycondensation with dibrominated DPP-based monomers bearing different aromatic units, which showed semiconducting behavior in OFETs and OPVs. In terms of purification of the obtained polymers, the efficiency of the removal of a Pd residue depends on the chemical structure of the polymers; coordination sites such as a carbonyl group and imine nitrogen make the Pd removal difficult. The polymer with a thiazolyl-flanked DPP unit shows long-wavelength absorption compared to phenyl- and pyridyl-flanked DPP units. DFT calculation showed that the characteristic physical properties of the thiazolylDPP polymer were caused by the delocalization of HOMO over all units owing to its coplanar structure of the main chain. The efficient synthetic method, direct arylation polycondensation, provided a series of DPP-based polymers in a simple fashion, leading to a comprehensive understanding of the effects of the aromatic group of the DPP unit on their physical properties. These insights provide important information for the molecular design of DPP-based polymers.

\section{ACKNOWLEDGEMENTS}

The authors thank the Chemical Analysis Center of University of Tsukuba for the measurements of NMR spectra, MALDI-TOF-MS, and ICP-MS. The authors also thank to Prof. Y. Nishihara and Prof. $\mathrm{H}$. Mori of Okayama University for the measurement of high-temperature GPC, and Prof. T. Koizumi and the Center for Advanced Materials Analysis, Technical Department, Tokyo Institute of Technology for the elemental analyses. The authors wish to thank Prof. S. Kagaya of University of Toyama for valuable advices for measurements of ICP-MS. This work was supported by Industrial Technology Research Grant Program in 2011 from New Energy and Industrial Technology Development Organization
(NEDO) of Japan, and partly supported by Grantin-Aid for Grant-in-Aid for Young Scientists (B) (15K17922), Challenging Exploratory Research (25620094) and Scientific Research (B) (25288052).

\section{REFERENCES}

1. Y. Li, P. Sonar, L. Murphy, W. Hong, Energy Environ. Sci. 2013, 6, 1684-1710.

2. C. B. Nielsen, M. Turbiez, I. McCulloch, Adv. Mater. 2013, 25, 1859-1880.

3. M. A. Naik, S. Patil, J. Polym. Sci. Part A: Polym. Chem. 2013, 51, 4241-4260.

4. W. Li, K. H. Hendriks, M. M. Wienk, R. A. J. Janssen, Acc. Chem. Res. 2016, 49, 78-85.

5. B. Tieke, A. R. Rabindranath, K. Zhang, Y. Zhu, Beilstein J. Org. Chem. 2010, 6, 830-845.

6. Z. Hao, A. Iqbal, Chem. Soc. Rev. 1997, 26, 203-213.

7. M. Grzybowski, D. T. Gryko, Adv. Optical Mater. 2015, 3, 280-320.

8. J. Kuwabara, T. Yamagata, T. Kanbara, Tetrahedron, 2010, 66, 3736-3741.

9. H. Bronstein, Z. Chen, R. S. Ashraf, W. Zhang, J. Du, J. R. Durrant, P. S. Tuladhar, K. Song, S. E. Watkins, Y. Geerts, M. M. Wienk, R. A. J. Janssen, T. Anthopoulos, H. Sirringhaus, M. Heeney, I. McCulloch, J. Am. Chem. Soc. 2011, 133, 3272-3275.

10. R. S. Ashraf, I. Meager, M. Nikolka, M. Kirkus, M. Planells, B. C. Schroeder, S. Holliday, M. Hurhangee, C. B. Nielsen, H. Sirringhaus, I. McCulloch, J. Am. Chem. Soc. 2015, 137, 1314-1321.

11. J. W. Jung, F. Liu, T. P. Russell, W. H. Jo, Chem. Commun. 2013, 49, 8495-8497.

12. B. Sun, W. Hong, Z. Yan, H. Aziz, Y. Li, Adv. Mater. 2014, 26, 2636-2642.

13. B. Carsten, J. M. Szarko, L. Lu, H. J. Son, F. He, Y. Y. Botros, L. X. Chen, L. Yu, Macromolecules 2012, 45, 6390-6395.

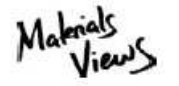

WWW.MATERIALSVIEWS.COM 
14. W. Li, W. S. C. Roelofs, M. Turbiez, M. M. Wienk, R. A. J. Janssen, Adv. Mater. 2014, 26, 3304-3309.

15. S. Kowalski, S. Allard, K. Zilberberg, T. Riedl, U. Scherf, Prog. Polym. Sci. 2013, 38, 1805-1814.

16. L. G. Mercier, M. Leclerc, Acc. Chem. Res. 2013, 46, 1597-1605.

17. K. Okamoto, J. Zhang, J. B. Housekeeper, S. R. Marder, C. K. Luscombe, Macromolecules 2013, 46, 8059-8078.

18. J. Kuwabara, T. Kanbara, J. Synth. Org. Chem. Jpn. 2014, 72, 1271-1277.

19. A. E. Rudenko, B. C. Thompson, J. Polym. Sci., Part A: Polym. Chem. 2015, 53, 135-147.

20. Q. Wang, R. Takita, Y. Kikuzaki, F. Ozawa, J. Am. Chem. Soc. 2010, 132, 11420-11421.

21. W. Lu, J. Kuwabara, T. Kanbara, Macromolecules 2011, 44, 1252-1255.

22. Y. Fujinami, J. Kuwabara, W. Lu, H. Hayashi, T. Kanbara, ACS Macro Lett. 2012, 1, 67-70.

23. P. Berrouard, A. Najari, A. Pron, D. Gendron, P.-O. Morin, J.-R. Pouliot, J. Veilleux, M. Leclerc, Angew. Chem., Int. Ed. 2012, 51, 2068-2071.

24. S. Kowalski, S. Allard, U. Scherf, ACS Macro Lett. 2012, 1, 465-468.

25. S.-W. Chang, H. Waters, J. Kettle, Z.-R. Kuo, C.-H. Li, C.-Y. Yu, M. Horie, Macromol. Rapid Commun. 2012, 33, 1927-1932.

26. M. Wakioka, N. Ichihara, Y. Kitano, F. Ozawa, Macromolecules 2014, 47, 626-631.

27. A. E. Rudenko, B. C. Thompson, Macromolecules 2015, 48, 569-575.

28. R. Matsidik, H. Komber, A. Luzio, M. Caironi, M. Sommer, J. Am. Chem. Soc. 2015, 137, 6705-6711.

29. T. Bura, P.-O. Morin, M. Leclerc, Macromolecules 2015, 48, 5614-5620.

30. J. Kuwabara, Y. Nohara, S. J. Choi, Y. Fujinami, W. Lu, K. Yoshimura, J. Oguma, K. Suenobu, T. Kanbara, Polym. Chem. 2013, 4, 947-953.
31. Q. Guo, J. Dong, D. Wan, D. Wu, J. You, Macromol. Rapid Commun. 2013, 34, 522527.

32. J.-R. Pouliot, L. G. Mercier, S. Caron, M. Leclerc, Macromol. Chem. Phys. 2013, 214, 453-457.

33. J.-R. Pouliot, B. Sun, M. Leduc, A. Najari, Y. Li, M. Leclerc, Polym. Chem. 2014, 6, 278-282.

34. Y. Gao, X. Zhang, H. Tian, J. Zhang, D. Yan, Y. Geng, F. Wang, Adv. Mater. 2015, 27, 6753-6759.

35. P. Homyak, Y. Liu, F. Liu, T. P. Russel, E. B. Coughlin, Macromolecules 2015, 48, 6978-6986.

36. S. Broll, F. Nübling, A. Luzio, D. Lentzas, H. Komber, M. Caironi, M. Sommer, Macromolecules 2015, 48, 7481-7488.

37. K. Wang, G. Wang, M. Wang, Macromol. Rapid Commun. 2015, 36, 2162-2170.

38. S.-Y. Liu, M.-M. Shi, J.-C. Huang, Z.-N. Jin, X.-L. Hu, J.-Y. Pan, H.-Y. Li, A. K.-Y. Jen, H.-Z. Chen, J. Mater. Chem. A 2013, 1, 2795-2805.

39. C. J. Mueller, C. R. Singh, M. Fried, S. Huettner, M. Thelakkat, Adv. Funct. Mater. 2015, 25, 2725-2736.

40. D. Caras-Quintero, P. Bäuerle, Chem. Commun. 2004, 926-927.

41. T. Yasuda, Y. Shinohara, T. Matsuda, L. Han, T. Ishi-i, J. Polym. Sci. Part A: Polym. Chem. 2013, 15, 2536-2544.

42. A. Kumar, A. Kumar, Polym. Chem. 2010, 1, 286-288.

43. K. Yamazaki, J. Kuwabara, T. Kanbara, Macromol. Rapid Commun. 2013, 34, 69-73.

44. L. A. Estrada, J. J. Deininger, G. D. Kamenov, J. R. Reynolds, ACS Macro Lett. 2013, 2, 869873.

45. S. J. Choi, J. Kuwabara, T. Kanbara, ACS Sustainable Chem. Eng. 2013, 1, 878-882.

46. J. Kuwabara, T. Yasuda, S. J. Choi, W. Lu, K. Yamazaki, S. Kagaya, L. Han, T. Kanbara, Adv. Funct. Mater. 2014, 24, 3226-3233. 
47. S. Hayashi, T. Koizumi, Polym. Chem. 2015, 6, 5036-5039.

48. C. J. Mueller, C. R. Singh, M. Thelakkat, J. Polym. Sci. Part B: Polym. Phys. 2016, 54, 639-648.

49. C. O. Kappe, Angew. Chem., Int. Ed. 2004, 43, 6250-6284.

50. W. Lu, J. Kuwabara, M. Kuramochi, T. Kanbara, J. Polym. Sci. Part A: Polym. Chem. 2015, 53, 1396-1402.

51. F. Lombeck, H. Komber, S. I. Gorelsky, M. Sommer, ACS Macro Lett. 2014, 3, 819-823.
52. S. Kowalski, S. Allard, U. Scherf, Macromol. Rapid Commun. 2015, 36, 1061-1068.

53. J. Kuwabara, M. Sakai, Q. Zhang, T. Kanbara, Org. Chem. Front. 2015, 2, 520-525.

54. K. T. Nielsen, H. Spanggaard, F. C. Krebs, Macromolecules 2005, 38, 1180-1189.

55. J. Kuwabara, T. Yasuda, N. Takase, T. Kanbara, ACS Appl. Mater. Interfaces 2016, 8, 1752-1758.

56. C. Bleiholder, R. Gleiter, D. B. Werz, H. Köppel, Inorg. Chem. 2007, 46, 2249-2260. 


\section{GRAPHICAL ABSTRACT}

\section{AUTHOR NAMES}

Junpei Kuwabara, Naoto Takase, Takeshi Yasuda, Takaki Kanbara

\section{TITLE}

Synthesis of Conjugated Polymers Possessing Diketopyrrolopyrrole (DPP) Units Bearing Phenyl, Pyridyl, and Thiazolyl Groups by Direct Arylation Polycondensation: Effects of Aromatic Groups in DPP on Physical Properties

\section{TEXT}

Direct arylation polycondensation of an EDOT derivative with dibrominated diketopyrrolopyrrole (DPP) monomers afforded conjugated polymers containing phenyl-, pyridyl-, and thiazolyl-flanked DPP units. Investigation on their physical properties revealed the effects of the aromatic group in the DPP units. The polymer bearing the thiazolyl-flanked DPP unit has a long-wavelength absorption property and high crystallinity owing to a coplanar structure of a main chain, compared with the polymers bearing phenyland pyridyl-flanked DPP units.

\section{Graphical Abstract for Table of Contents}

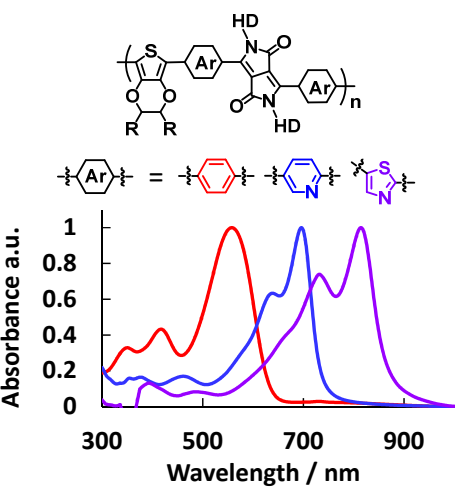

